\title{
Target-controlled infusion of remifentanil for conscious sedation during spinal anesthesia
}

\author{
Sung Hye Byun, Doo Youn Hwang, Seong Wook Hong, and Si Oh Kim \\ Department of Anesthesiology and Pain Medicine, Kyungpook National University School of Medicine, Daegu, Korea
}

Background: The aim of this study was to define the optimal target concentration of remifentanil which effectively achieves conscious sedation without significant vital sign changes and side effects during spinal anesthesia.

Methods: Sixty patients underwent spinal anesthesia with $0.5 \%$ hyperbaric bupivacaine $(8-16 \mathrm{mg})$, and were infused with a target controlled infusion (TCI) of remifentanil at $1.0 \mathrm{ng} / \mathrm{ml}$ (group R10, $\mathrm{n}=15$ ), $2.0 \mathrm{ng} / \mathrm{ml}$ (group R20, $\mathrm{n}=15$ ), $3.0 \mathrm{ng} / \mathrm{ml}$ (group R30, $\mathrm{n}=15$ ), and $3.5 \mathrm{ng} / \mathrm{ml}$ (group R35, $\mathrm{n}=15$ ). Observer's assessment of alertness/sedation (OAA/S) scale, the bispectral index (BIS), anxiety levels and infusion rate of remifentanil were monitored during the operation. Results: OAA/S scale was significantly lower in groups R30 (3.96) and R35 (3.34) than groups R10 (4.31) and R20 (4.26). Incidence of intraoperative respiratory depression events, post operative nausea and vomiting were significantly higher in group R35 than the other groups. There were no significant differences in BIS, anxiety level and incidences of recall of the operative procedure among the groups.

Conclusions: We conclude that the TCI of remifentanil at $3.0 \mathrm{ng} / \mathrm{ml}$ produces an effective sedation and anti-anxiety effects without significant side effects during spinal anesthesia. (Korean J Anesthesiol 2011; 61: 195-200)

Key Words: Conscious sedation, Remifentanil, Spinal anesthesia, Target controlled Infusion.

\section{Introduction}

Regional anesthesia leaves patients awake, anxious and it can also cause discomfort and stress during the operative procedure. To minimize these complaints, sedatives such as midazolam or propofol may be used singly. In addition, combination administration with opioids including alfentanil or remifentanil can help the patients to be relaxed and cooperative.
Propofol is commonly used for conscious sedation during local or regional anesthesia. Disadvantages of propofol include moderate pain during intravenous injection and involuntary movement during the operation. But, it produces an excellent sedative effect at a blood concentration of $0.9 \mu \mathrm{g} / \mathrm{ml}$ during spinal anesthesia. This value is significantly lower than $1.8 \mu \mathrm{g} /$ $\mathrm{ml}$ during local anesthesia for conscious sedation [1]. Because spinal anesthesia itself potentiates the sedative effects due to the deafferentation mechanism in the early phase as well as a

Received: January 13, 2011. Revised: February 21, 2011. Accepted: February 25, 2011.

Corresponding author: Seong Wook Hong, M.D., Department of Anesthesiology and Pain Medicine, Kyungpook National University School of Medicine, 50, Samdeok-dong 2-ga, Jung-gu, Daegu 700-721, Korea. Tel: 82-53-420-5864, Fax: 82-53-426-2760, E-mail: hsuaa@naver.com (c) This is an open-access article distributed under the terms of the Creative Commons Attribution Non-Commercial License (http:// creativecommons.org/licenses/by-nc/3.0/), which permits unrestricted non-commercial use, distribution, and reproduction in any medium, provided the original work is properly cited. 
direct action of local anesthetics to the brain in the late phase [2], requirement of the sedatives and anesthestics can be reduced during spinal anesthesia [3]. Therefore, a single infusion of remifentanil has a similar effect to combination use with a small dose of sedatives for conscious sedation [4]. This method is able to reduce the side effect of propofol.

However, remifentanil can cause respiratory depression, nausea and vomiting which are dose-related [4]. Therefore, it is necessary to study the optimal concentrations of remifentanil that are effective in achieving proper sedation as well as minimizing side effects.

The purpose of this study was to determine whether a single infusion of remifentanil was useful for conscious sedation during spinal anesthesia by evaluating the sedative score, anxiety level and the incidence of side effects while patients were infused with a target controlled infusion (TCI) of remifentanil at concentration of $1.0 \mathrm{ng} / \mathrm{ml}, 2.0 \mathrm{ng} / \mathrm{ml}, 3.0$ $\mathrm{ng} / \mathrm{ml}$ and $3.5 \mathrm{ng} / \mathrm{ml}$. We also investigated the optimal target concentration of remifentanil which effectively achieves conscious sedation without significant changes in vital signs and side effects.

\section{Materials and Methods}

A total of 60 patients (men and women), aged 20 to 65 years, who were scheduled for elective surgery under spinal anesthesia and had a ASA physical status I and II, were enrolled into the study after written informed consent was obtained from each patient. The patients were divided into four groups of 15 persons each. The following patients were excluded: those with significant cardiac, hepatic, renal or psychiatric disease, those with prior abuse of opioids or sedatives and those currently using anti-hypertensive drugs. Patients with heart rate lower than 50 or higher than 100 beats/min and systolic blood pressure higher than $160 \mathrm{mmHg}$ or lower than $80 \mathrm{mmHg}$ at pre-induction were also excluded.

All patients did not receive any premedication and at their arrival into the operating room they were intravenously injected with $12 \mathrm{ml} / \mathrm{kg}$ Hartman solution, while oxygen was provided at $5 \mathrm{~L} / \mathrm{min}$ using face mask ventilation. Electrocardiogam $(\mathrm{EKG})$, heart rate (HR) and oxygen saturation were monitored continuously and non-invasive blood pressure (BP) was measured at 5 minute intervals until the end of the operation. The bispectral index scale (BIS) was assessed continuously by a sensor placed on the patient's forehead and a BIS monitor (A2000 BIS monitor, Aspect Medical System, USA).

We performed spinal anesthesia with $8-16 \mathrm{mg}$ of $0.5 \%$ hyperbaric bupivacaine and the level of sensory block was evaluated 10-12 minutes after the induction of anesthesia. When the operation began, remifentanil infusion started with a target-controlled infusion system (Orchestra ${ }^{\circledR}$, Fresenius Vial, France) using Minto's model. The target effect-site concentration of remifentanil was set at $1.0 \mathrm{ng} / \mathrm{ml}, 2.0 \mathrm{ng} / \mathrm{ml}, 3.0 \mathrm{ng} / \mathrm{ml}$ and $3.5 \mathrm{ng} / \mathrm{ml}$ in groups R10, R20, R30 and R35, respectively.

We assessed the degree of sedation using BIS and observer's assessment of alertness/sedation (OAA/S) scale (5: completely alert, 4: drowsy, 3: with eyes close, but responsive to verbal stimulation promptly, 2: with eyes close, only responsive to physical stimulation, 1: unresponsive to physical stimulation) and also measured anxiety (1: anxious and uncooperative, 2: not completely cooperative, with emotional change 3 : cooperative and able to perform the operation) at 5 minute intervals. Infusion rate $(\mu \mathrm{g} / \mathrm{kg} / \mathrm{min})$ was calculated using the total infusion dose of remifentanil divided by patient weight per infusion time and these values did not need to be compared among the groups because they were proportional to their setting concentration. After the cessation of remifentanil infusion, response to verbal commands was checked. An hour after the end of the operation, we noted incidence of recall of the operative procedure in a recovery room. We recorded the remifentanil-associated side effects such as hypotension, bradycardia and respiratory depression during the intraoperative and postoperative period. If BP decreased to $30 \%$ of the first measured BP, this was defined as hypotension and a HR below 50 beats/min was defined as bradycardia. If the oxygen saturation decreased below $95 \%$ with oxygen given a $5 \mathrm{~L} / \mathrm{min}$, then it was regarded as respiratory depression. In addition, we checked whether confusion, headache, dizziness, nausea and vomiting developed in recovery room. HR, systolic arterial pressure (SAP) and diastolic arterial pressure (DAP) were measured at 5 minute intervals for an hour after initiation of remifentanil infusion and these values were compared among the groups.

All results were shown as mean \pm standard error (SE) and analysis of variance (ANOVA) was performed on the demographic data, using the one-way ANOVA among the groups. A Kruskal-Wallis test was applied to compare sedation scores. For a comparison of side effects during the intraoperative and postoperative period, a $x^{2}$-test was applied. For HR, SAP, DAP and sedation score measurements, Tukey's was applied to determine differences in the groups. $\mathrm{P}$ values $<0.05$ were considered statistically significant.

\section{Results}

Among the groups, there were no significant differences in sex, age, weight and height, there were also no significant differences in the dose of administrated bupivacaine and the level of anesthesia (Table 1).

The OAA/S score in group R35 were significantly lower than in the other three groups and the value in group R30 was also 
Table 1. Patient Characteristics

\begin{tabular}{lcccc}
\hline & $\mathrm{R} 10(\mathrm{n}=15)$ & $\mathrm{R} 20(\mathrm{n}=15)$ & $\mathrm{R} 30(\mathrm{n}=15)$ & $\mathrm{R} 35(\mathrm{n}=15)$ \\
\hline Sex (M/F) & $11 / 4$ & $13 / 2$ & $11 / 4$ & $13 / 2$ \\
Age (yr) & $45.4 \pm 2.5$ & $42.8 \pm 3.9$ & $68.7 \pm 2.4$ & $43.2 \pm 4.5$ \\
Weight (kg) & $66.3 \pm 2.5$ & $70.9 \pm 2.5$ & $64.4 \pm 2.0$ & $68.2 \pm 3.3$ \\
Height (cm) & $166.8 \pm 2.3$ & $170.1 \pm 2.0$ & $66.1 \pm 1.8$ & $167.0 \pm 2.6$ \\
Duration of surgery (min) & $72 \pm 6.5$ & $66.3 \pm 4.9$ & $10.8 \pm 0.3$ & $77.1 \pm 5.8$ \\
Bupivacaine used (mg) & $10.5 \pm 0.3$ & $10.3 \pm 0.2$ & $\mathrm{~T} 6(\mathrm{~T} 4-10)$ & $10.9 \pm 0.3$ \\
Level of anesthesia & $\mathrm{T} 6(\mathrm{~T} 4-10)$ & $\mathrm{T} 6(\mathrm{~T} 4-10)$ & $\mathrm{T} 6(\mathrm{~T} 4-10)$ \\
\hline
\end{tabular}

Values are mean \pm SE or median (range). R10, R20, R30 and R35 represent target concentrations of remifentanil $(1.0 \mathrm{ng} / \mathrm{ml}, 2.0 \mathrm{ng} / \mathrm{ml}, 3.0 \mathrm{ng} / \mathrm{ml}$ and $3.5 \mathrm{ng} / \mathrm{ml}$, respectively) in each of target controlled infusion groups.

Table 2. Sedation Data

\begin{tabular}{lcccc}
\hline & $\mathrm{R} 10(\mathrm{n}=15)$ & $\mathrm{R} 20(\mathrm{n}=15)$ & $\mathrm{R} 30(\mathrm{n}=15)$ & $\mathrm{R} 35(\mathrm{n}=15)$ \\
\hline OAA/S scale & $4.31(5-3)$ & $4.26(5-3)$ & $3.96(5-2)^{*}$ & $3.34(5-2)^{*, \dagger}$ \\
Anxiety level & $3.0(2-3)$ & $3.0(2-3)$ & $92.5 \pm 0.7$ & 3.0 \\
Bispectral index & $93.9 \pm 0.4$ & $92.3 \pm 0.6$ & $0.13 \pm 0.003$ & $88.6 \pm 0.8$ \\
Infusion rate $(\mu \mathrm{g} / \mathrm{kg} / \mathrm{min})$ & $0.04 \pm 0.002$ & $0.08 \pm 0.003$ & 14 & $0.15 \pm 0.006$ \\
End of infusion to response & 15 & 15 & 8 & 13 \\
$\quad$ to verbal command (n) & $13^{\dagger}$ & 10 & 8 \\
Recall of operative procedure $(\mathrm{n})$ & & & 8 \\
\hline
\end{tabular}

Values are mean $\pm \mathrm{SE}$ or median (range). R10, R20, R30 and R35 represent target concentrations of remifentanil $(1.0 \mathrm{ng} / \mathrm{ml}, 2.0 \mathrm{ng} / \mathrm{ml}, 3.0 \mathrm{ng} / \mathrm{ml}$ and $3.5 \mathrm{ng} / \mathrm{ml}$, respectively) in each of target controlled infusion groups. $* \mathrm{P}<0.05$ compared with group R10 and R20. ${ }^{\dagger} \mathrm{P}<0.05$ compared with group R10, R20 and R30. ${ }^{\ddagger} \mathrm{P}<0.05$ compared with group R20, R30 and R35.

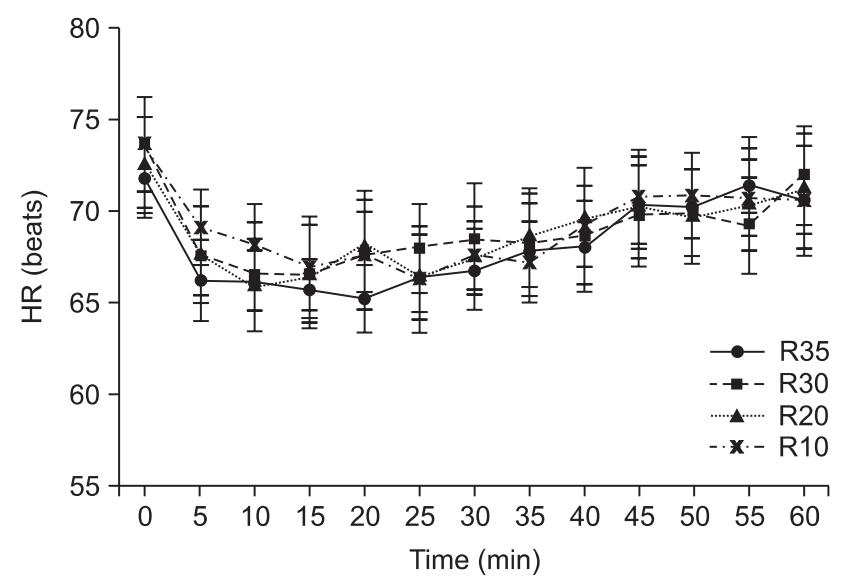

Fig. 1. Changes of heart rate are shown up to $60 \mathrm{~min}$ after administration of remifentanil. Data are expressed as mean \pm SE. R10, R20, R30 and R35 represent target concentrations of remifentanil of 1.0 $\mathrm{ng} / \mathrm{ml}, 2.0 \mathrm{ng} / \mathrm{ml}, 3.0 \mathrm{ng} / \mathrm{ml}$ and $3.5 \mathrm{ng} / \mathrm{ml}$, respectively in each of target controlled infusion group.

significantly lower than in groups R10 and R20 $(\mathrm{P}<0.05)$. There were no significant differences in BIS and the anxiety scale, and BIS was overly high even in the sedative condition. The infusion rate of remifentanil was $0.04 \mu \mathrm{g} / \mathrm{kg} / \mathrm{min}, 0.08 \mu \mathrm{g} / \mathrm{kg} / \mathrm{min}, 0.13$ $\mu \mathrm{g} / \mathrm{kg} / \mathrm{min}$ and $0.15 \mu \mathrm{g} / \mathrm{kg} / \mathrm{min}$ on average in groups R10, R20, R30 and R35, respectively. Ninety-five percent of the patients responded to a verbal command immediately after the stop of remifentanil infusion and there was no significant difference

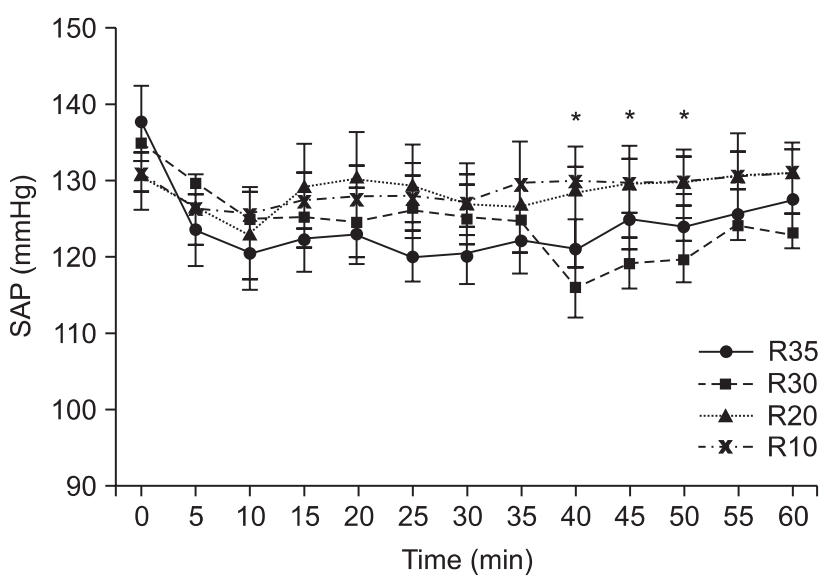

Fig. 2. Changes of systolic arterial pressure are shown up to $60 \mathrm{~min}$ after administration of remifentanil. Data are expressed as mean \pm SE. R10, R20, R30 and R35 represent target concentrations of remifentanil $1.0 \mathrm{ng} / \mathrm{ml}, 2.0 \mathrm{ng} / \mathrm{ml}, 3.0 \mathrm{ng} / \mathrm{ml}$ and $3.5 \mathrm{ng} / \mathrm{ml}$, respectively in each of target controlled infusion groups. *Group R30 was significantly different compared with group R10 $(\mathrm{P}<0.05)$.

among the groups. Incidence of recall of the operative procedure was significantly higher in group R10 than in the other groups $(\mathrm{P}<0.05)$ (Table 2$)$.

With respect to hemodynamic changes during the operation, HR showed no significant differences among the groups (Fig. 1). SAP decreased significantly in group R30 at 40-50 minutes after the induction of anesthesia compared with group R10 (Fig. 2), 


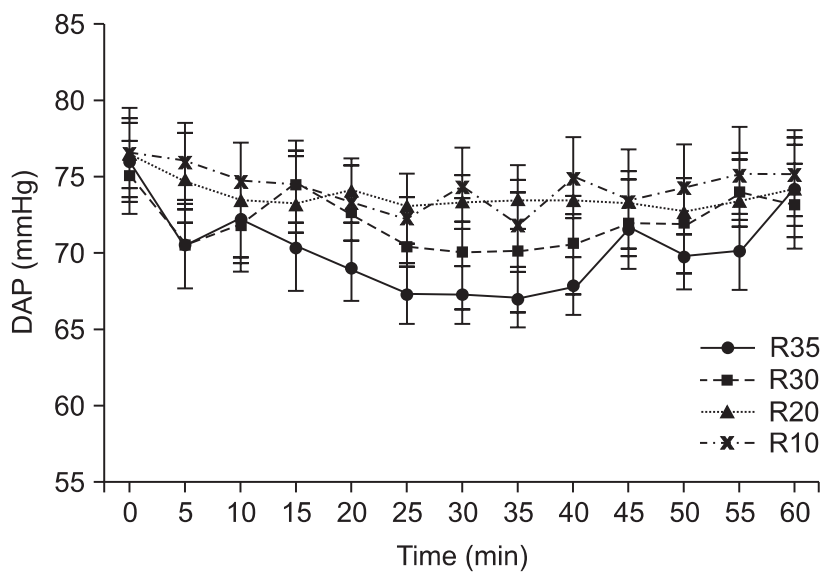

Fig. 3. The changes of diastolic arterial pressure are shown up to 60 min after administration of remifentanil. Data are expressed as mean \pm SE. R10, R20, R30 and R35 represent target concentrations of remifentanil $1.0 \mathrm{ng} / \mathrm{ml}, 2.0 \mathrm{ng} / \mathrm{ml}, 3.0 \mathrm{ng} / \mathrm{ml}$ and $3.5 \mathrm{ng} / \mathrm{ml}$, respectively in each of target controlled infusion groups.

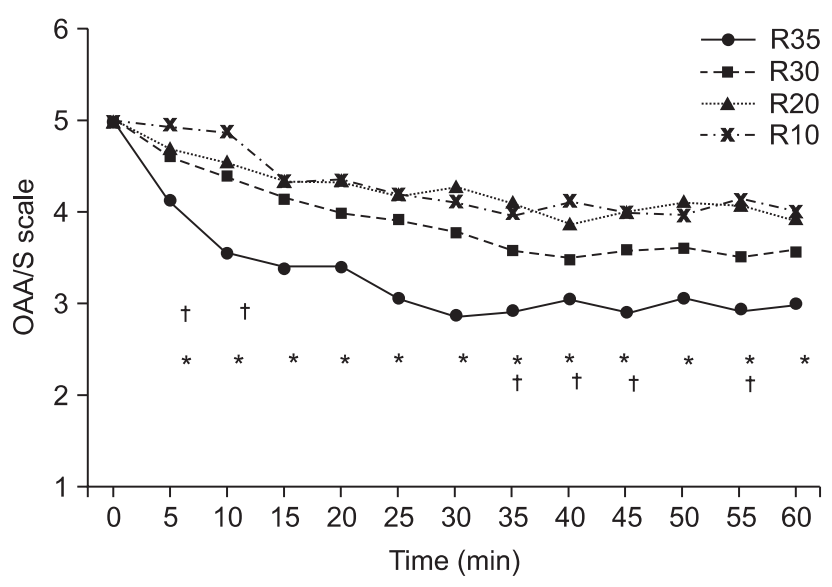

Fig. 4. The changes of sedation score are shown up to $60 \mathrm{~min}$ after administration of remifentanil. Data are expressed as mean \pm SE. R10, R20, R30 and R35 represent target concentrations of remifentanil $1.0 \mathrm{ng} / \mathrm{ml}, 2.0 \mathrm{ng} / \mathrm{ml}, 3.0 \mathrm{ng} / \mathrm{ml}$ and $3.5 \mathrm{ng} / \mathrm{ml}$, respectively in each of target controlled infusion groups. *Group R35 was significantly different compared with group R10, R20 and R30 (P < 0.05), ${ }^{\dagger}$ Group $\mathrm{R} 30$ was significantly different compared with group R10 $(\mathrm{P}<0.05)$.

but DAP showed no significant differences among the groups (Fig. 3).

OAA/S scores were significantly lower in group R35 than in groups R10, R20 and R30 at 50-60 minutes after induction. Group R30 showed a significant reduction in the OAA/S scale compared to group R10 at 5-10 minutes, 35-45 minutes and 55 minutes after induction (Fig. 4).

Hypotension was observed in $7 \%$ of R20 and 13\% of R35 and bradycardia seen in 13\% of R20 and 13\% of R35 patients during the operation. Intraoperative respiratory depression developed in $20 \%$ of R30 and $47 \%$ of R35 patients. Among these, only the
Table 3. Incidences of Perioperative Side Effects

\begin{tabular}{lcccc}
\hline & $\begin{array}{c}\mathrm{R} 10 \\
(\mathrm{n}=15)\end{array}$ & $\begin{array}{c}\mathrm{R} 20 \\
(\mathrm{n}=15)\end{array}$ & $\begin{array}{c}\mathrm{R} 30 \\
(\mathrm{n}=15)\end{array}$ & $\begin{array}{c}\mathrm{R} 35 \\
(\mathrm{n}=15)\end{array}$ \\
\hline $\begin{array}{l}\text { Intraoperative } \\
\text { Hypotension }\end{array}$ & 0 & 1 & 0 & 2 \\
$\quad$ Bradycardia & 0 & 2 & 2 & 4 \\
$\mathrm{SpO}_{2}<95 \%$ & 0 & 0 & 3 & $7^{*}$ \\
$\quad$ Incoluntary movement & 0 & 0 & 0 & 0 \\
Recovery & & & & \\
Confusion & 0 & 0 & 1 & 0 \\
$\quad$ Headache & 0 & 1 & 1 & 1 \\
$\quad$ Dizziness & 1 & 1 & 1 & 5 \\
Nausea and vomiting & 2 & 4 & 4 & $9 *$ \\
\hline
\end{tabular}

R10, R20, R30 and R35 represent target concentrations of remifentanil (1.0 ng/ml, $2.0 \mathrm{ng} / \mathrm{ml}, 3.0 \mathrm{ng} / \mathrm{ml}$ and $3.5 \mathrm{ng} / \mathrm{ml}$, respectively) in each of target controlled infusion groups. ${ }^{*} \mathrm{P}<0.05$ compared with group R10, R20 and R30.

incidence in respiratory depression was significantly higher in group R35 compared to the other groups $(\mathrm{P}<0.05)$. Involuntary movement was absent during the operations, so there were no significant differences among the groups.

Dizziness in recovery room was more frequent in the group R35 (30\%) than in the other three groups (6\%), but this did not reach statistical significance. Incidence of nausea and vomiting in group R35 was significantly higher than in the other three groups $(\mathrm{P}<0.05)$. There were no significant differences between the groups for confusion and headaches when monitored in the recovery room (Table 3 ).

\section{Discussion}

Conscious sedation is achieved by administering a drug that depresses the central nervous system (CNS) and it induces a state that allows the patients to tolerate procedures while easily maintaining responses to command [5]. For the patients who receive regional anesthesia, conscious sedation facilitates the procedure by reducing anxiety, pain and noxious stimuli while allowing maintenance of airway control independently. In addition, this method keeps the protective reflex, stabilizes vital signs and better promotes recovery. Conscious sedation is much more safe than deep sedation because the complications around the operation are rare compared to deep sedation which has incidence rates ranging from $25-75 \%$ [6]. Therefore, conscious sedation is apprpriate for patients during regional anesthesia.

Spinal and epidural anesthesia reduce the requirements for intravenous or inhaled anesthetics [3] due to the decrease of afferent inputs in the reticular activating system [7]. Midazolam [8], isoflurane [9], sevoflurane [10] have therefore been reported to have decreased use during anesthesia. Particularly with spinal anesthesia using bupivacaine, it has been reported that 
a high level block was associated with increased sedation [7]. In our study, bupivacaine was used during spinal anesthesia, and dose as well as the level of block showed no significant differences among the groups, so we could ignore the difference of sedation score caused by the level of block.

Propofol, which is a commonly used sedative during conscious sedation, allows the depth of anesthesia to change immediately by rapid control of the blood concentration using TCI [1]. Despite an excellent amnesic effect and low incidence of nausea and vomiting, propofol has no analgesic effect and produces undesirable effects such as involuntary movement. Its powerful amnesic effect is also sometimes undesirable if the patient wants to know about the procedures during operation [11].

Opioids are commonly used in monitored anesthesia care (MAC) and for pain relief during regional or general anesthesia. Of these, remifentanil which is a $\mu$ receptor agonist, not only has rapid onset of analgesic action but also has a fast offset of action due to non-specific esterases. Its half-life is 9.5 minutes [12] and context-sensitive half-time remains consistent even after longterm infusions [13]. The unique properties of remifentanil result in hemodynamic stability with analgesic effects necessary for outpatient anesthesia [14]. Mullejans et al. [15] reported that only $30 \%$ of the patients on long-term mechanical ventilation in the ICU demanded sedatives like propofol to be added with remifentanil, while the other patients could stay in comfort with remifentanil by itself. Since most of the distress of the patients was due to pain, analgesia-based sedation techniques were actually more useful to keep the patients comfortable than hypnotic-based sedation [15]. In other words, it was suggested that the manipulation of the analgesic dose by adding a sedative only might be more desirable than minimizing the dose of analgesics for optimal sedation. Hwang et al. [16] also reported that analgesia-based sedation using remifentanil satisfied the patients and the operators during endoscopic discectomy under conscious sedation because of an adequate analgesic effect while avoiding excessive sedation [16].

Fortunately, there was no patient who complained of pain during the surgery in our study. But if there are patients who feel the pain and discomfort due to an low block levels from unsuccessful spinal anesthesia or protracted operation, analgesics must be preferable to excessive sedatives for pain relief.

However remifentanil may reduce the patient's satisfaction owing to respiratory depression, nausea, vomiting and low incidence of amnesia [17]. Mingus et al. [4] reported that, while remifentanil had better analgesic effects without excessive sedation than propofol, it had more frequent side effects including respiratory depression, nausea and vomiting, and they recommended dose reduction for elimination of these side effects. In a study by Akcaboy et al. [18], the patients and the operators using remifentanil were better satisfied than the group receiving propofol because of the adequate sedation, analgesia and rapid recovery during MAC for colonoscopy. They also reported respiratory depression as a typical complication of remifentanil and this was reduced by means of the low dose infusion of remifentanil.

We tried to administer remifentanil solely without propofol for sedation under spinal anesthesia in this study based on the fact that spinal anesthesia reduces the requirement of intravenous sedatives due to decreased afferent inputs of the reticular activating system during spinal anesthesia, Consequently, a single infusion of remifentanil was found to be excellent in inducing a sedative effect. Remifentanil TCI at 3.0 $\mathrm{ng} / \mathrm{ml}$ and $3.5 \mathrm{ng} / \mathrm{ml}$ was responsible for significant decreases in OAA/S scores (3.96 and 3.34, respectively), similar to the $\mathrm{OAA} / \mathrm{S}$ scores of 3 and 4 targeting conscious sedation. These scores were nearly identical to a value of 3.8 in a group using propofol TCI under spinal anesthesia for conscious sedation [1]. In other words, when OAA/S scores were used to assess the degree of sedation, the score for propofol TCI with $0.9 \mu \mathrm{g} / \mathrm{ml}$ was not significantly different compared to a remifentanil TCI at $3.0 \mathrm{ng} / \mathrm{ml}$ and $3.5 \mathrm{ng} / \mathrm{ml}$. But the BIS value of 92.5 and 88.6 were recorded in the remifentanil groups, while the propofol group's BIS score was 73.4 [1]. These results showed that BIS could not reflect the degree of sedation when using remifentanil because BIS could not properly reflect sedation which was achieved by remifentanil or spinal anesthesia, whereas propofol-induced sedation could be reflected in BIS scores [19]. Most patients responded to a verbal command promptly after stopping the remifentanil infusion, so there was no risk of delayed recovery. The incidence of recall of the operative procedure was $53-86 \%$ which was significantly higher than the incidence rate of $15 \%$ in the group using propofol TCI [1]. There was no significant increase in the amnesic effect, remifentanil produced only analgesia without amnesia.

HR, SAP and DAP decreased as the amount of remifentanil infusion increased, but there were no significant differences. These results showed that remifentanil could maintain hemodynamic stability with only a minimal impact on cardiovascular system at the low concentrations for sedation. However, more studies are needed to investigate the hemodynamic changes in the elderly, in systemically ill patients and in groups at higher concentrations of remifentanil as well.

Since common side effects of remifentanil including bradycardia, hypoxia $\left(\mathrm{SpO}_{2}<95 \%\right)$, postoperative dizziness, nausea and vomiting were more frequent in the remifentanil TCI group receiving $3.5 \mathrm{ng} / \mathrm{ml}$ compared to the other groups, the adequate concentration of remifentanil for sedation during spinal anesthesia is thought to be $3.0 \mathrm{ng} / \mathrm{ml}$. When respiratory depression developed, though, the patients recovered the $\mathrm{SpO}_{2}$ 
value higher than $95 \%$ within $1-2$ minutes by encouraging the patients to breathe deeply. For hypotension, fluid loading was performed initially and then low BP recovered within 5 minutes without the need of ephedrine. Bradycardia recovered within 5 minutes without any particular treatment. And postoperative nausea and vomiting were diminished after intravenous administration with $4 \mathrm{mg}$ of ondansetron.

In conclusion, remifentanil produced the excellent sedative effect as an alternative to propofol. However the more powerful sedative effect was associated with the higher incidences of side effects, especially respiratory depression, nausea and vomiting so it is necessary carefully chose the doses for administration. We conclude that a single infusion of remifentanil is useful during spinal anesthesia using hyperbaric bupivacaine, and the TCI of remifentanil at $3.0 \mathrm{ng} / \mathrm{ml}$ is thought to be most appropriate considering the minimal hemodynamic change and side effects.

\section{References}

1. Kim DH, Sohn BK. Target-Controlled infusion of propofol for conscious sedation using BIS monitor. Korean J Anesthesiol 2000; 38: 8-13.

2. Pollock JE, Neal JM, Liu SS, Burkhead D, Polissar N. Sedation during spinal anesthesia. Anesthesiology 2000; 93: 728-34.

3. Tverskoy M, Shifrin V, Finger J, Fleyshman G, Kissin I. Effect of epidural bupivacaine block on midazolam hypnotic requirements. Reg Anesth 1996; 21: 209-13.

4. Mingus ML, Monk TG, Gold MI, Jenkins W, Roland C. Remifentanil versus propofol as adjuncts to regional anesthesia. J Clin Anesth 1998; 10: 46-53.

5. Irwin MG, Thompson N, Kenny GN. Patient-maintained propofol sedation. Assessment of a target-cotrolled infusion system. Anaesthesia 1997; 52: 525-30.

6. SáRêgo MM, White PF. Monitored anesthesia care. In: Anesthesia. 5th ed. Edited by Miller RD: Philadelphia, Churchill-Livingstone. 2000, pp 273-376.

7. Gentili M, Huu PC, Enel D, Hollande J, Bonnet F. Sedation depends on the level of sensory block induced by spinal anaesthesia. Br J Anaesth 1998; 81: 970-1.

8. Ben-David B, Vaida S, Gaitini L. The influence of high spinal anesthesia on sensitivity to midazolam sedation. Anesth Analg 1995; 81: 525-8.

9. Inagaki Y, Mashimo T, Kuzukawa A, Tsuda Y, Yoshiya I. Epidural lidocaine delays arousal from isoflurane anesthesia. Anesth Analg 1994; 79: 368-72.

10. Hodgson PS, Liu SS, Gras TW. Does epidural anesthesia have general anesthetic effects? A prospective, randomized, doubleblind, placebo-controlled trial. Anesthesiology 1999; 91: 1687-92.

11. White PF, Negus JB. Sedative infusions during local and regional anesthesia: a comparison of midazolam and propofol. J Clin Anesth 1991; 3: 32-9.

12. Rosow C. Remifentanil: a unique opioid analgesic. Anesthesiology 1993; 79: 875-6.

13. Kapila A, Glass PS, Jacobs JR, Muir KT, Hermann DJ, Shiraishi M, et al. Measured context-sensitive half-times of remifentanil and alfentanil. Anesthesiology 1995; 83: 968-75.

14. Ramos-Zabala A, Pérez-Mencía MT, Fernández-García R, CascalesNúñez MR. Anesthesia technique for outpatient facial laser resurfacing. Lasers Surg Med 2004; 34: 269-72.

15. Muellejans B, López A, Cross MH, Bonome C, Morrison L, Kirkham AJ. Remifentanil versus fentanyl for analgesia based sedation to provide patient comfort in the intensive care unit: a randomized, double-blind controlled trial. Crit Care 2004; 8: R1-R11.

16. Hwang KI, Lee HY, Shim KD, Kim DY, Shim CS, Lee SH. Analgesiabased sedation using remifentanil during percutaneous endoscopic lumbar discectomy. Korean J Anesthesiol 2006; 50: 36-41.

17. Servin FS, Raeder JC, Merle JC, Wattwil M, Hanson AL, Lauwers $\mathrm{MH}$, et al. Remifentanil sedation compared with propofol during regional anaesthesia. Acta Anaesthesiol Scand 2002; 46: 309-15.

18. Akcaboy ZN, Akcaboy EY, Albayrak D, Altinoren B, Dikmen B, Gogus N. Can remifentanil be better choice than propofol for colonoscopy during monitored anesthesia care? Acta Anaesthesiol Scand 2006; 50: 736-41.

19. Kil HY, Hwang SM, Lee SJ, Baik SW, Park YJ. An experience of BIS monitoring for the measurement of hypnotic state during general anesthesia using a propofol TCI. Korean J Anesthesiol 1999; 36: 72935 . 